\title{
MEMÓRIAS E NARRATIVAS HÍBRIDAS NO CINEMA BRASILEIRO CONTEMPORÂNEO
}

\author{
Wendell Marcel Alves da Costa \\ Orientadora: Profa. Dra. Maria Helena Braga e Vaz da Costa \\ Graduando em Ciências Sociais - UFRN \\ Bolsista IC/CNPq \\ E-mail: marcell.wendell@hotmail.com
}

\section{RESUMO}

Este trabalho tem por objetivo compreender como são construídas as memórias a respeito de uma cidade brasileira - Ceilândia-DF - tendo como base a produção e representação cinematográfica através da narrativa do espaço urbano. Parte-se aqui do princípio que as narrativas da cidade de Ceilândia nos filmes brasileiros, A Cidade é uma Só (2012) e Branco Sai, Preto Fica (2015), ambos do cineasta Adirley Queirós, são híbridas. Assim, privilegiaremos a análise desses dois filmes como dispositivos híbridos que abarcam duas formas narrativas: ficcional e documental. Os filmes analisados propiciam discussões acerca das dualidades entre periferia/cidade, poder/empoderamento e história cultural/memórias afetivas; questões que envolvem a apropriação do espaço da cidade e seus efeitos de deslocamentos e as construções das narrativas que dão margem a uma interpretação do discurso fílmico sobre os movimentos espaciais da região de Ceilândia.

Palavras-chave: Espaço Urbano, Narrativas Híbridas, Memórias.

\section{INTRODUÇÃO}

Este trabalho tem por objetivo compreender como são construídas as memórias a respeito de uma cidade brasileira - Ceilândia-DF - tendo como base a representação cinematográfica e da narrativa do espaço urbano. Parte-se aqui do princípio que as narrativas da cidade de Ceilândia nos filmes brasileiros, A Cidade é uma Só? (2011) e Branco Sai, Preto Fica (2015), ambos do cineasta Adirley Queirós, são híbridas. Os filmes servem aqui como um painel imagético por meio do qual pode inferir discussões acerca do espaço urbano, do imaginário, da representação fílmica em relação com a memória, já que o filme se configura em um dispositivo que é, por excelência, carregado de valor simbólico e de ideologia.

Privilegiaremos a análise desses dois filmes como dispositivos híbridos que abarcam duas formas narrativas: ficcional e documental, e que propiciam discussões acerca de dualidades como periferia/cidade, poder/empoderamento e história cultural/memórias afetivas. Questões estas que envolvem a apropriação do espaço da cidade e seus efeitos de deslocamentos e as construções das narrativas que dão margem a uma interpretação do discurso fílmico sobre os movimentos socioespaciais da região da cidade de Ceilândia-DF.

Percebemos aqui o discurso fílmico como uma congregação simbólica que diz sobre um acontecimento político, trazendo o conceito de memória como um ponto de 


\section{SEMINÁRIO DE PESQUISA EM CIÊNCIAS HUMANAS - SEPECH \\ Humanidades, Estado e desafios didático-científicos \\ Londrina, 27 a 29 de julho de 2016}

partida para a análise teórica. Como objetos empíricos, os filmes colocam-se como produtos híbridos cinematográficos, assim sendo, os conceitos de fronteira e de cinema periférico também ganham espaço neste trabalho. Isto porque contribuem conceitualmente para definir um plano teórico fundamentado nos estudos acerca dessas definições iniciais.

O foco de análise, enfim, recai na interpretação da imagem cinematográfica como substrato do imaginário, colocando em destaque as relações envolvendo a construção do espaço da cidade de Ceilândia. A fundamentação teórica é proveniente dos estudos realizados na área dos fenômenos culturais, da imagem como dispositivo de análise, e parte do imaginário social, e a compreensão do espaço e da paisagem fílmicas como canais de representação da construção de imaginários e de identidades culturais.

\section{MEMÓRIAS E NARRATIVAS HÍBRIDAS EM $A$ CIDADE É UMA SÓ? E BRANCO SAI, PRETO FICA}

O cinema comumente emprega em seus enredos versões da realidade por meio de narrativas que falam sobre aspectos da sociedade. É no emprego de narrativas híbridas que os filmes discursam sobre um determinado momento histórico ganham espaço no sentido de reconhecer, e discutir sobre, determinado "pedaço" da memória coletiva.

Neste trabalho, entendemos a imagem cinematográfica como uma construção conceitual, cultural (e moral) e seus sentidos de verdade estãoabsortos na certeza de que a imagem mune-se de códigos, símbolos e noções sociais para se autolegitimar no mundo social. Dessa forma, a imagem cinematográfica é mais uma interpretação simbólica e metafórica do que uma descrição fidedigna do real.

No aspecto da memória, temos em vista que esta é apenas significada quando o passado produz imaginários e sentidos afetivos sobre determinados acontecimentos, sejam eles coletivos ou individuais. Assim, é necessário entender a memória e a construção da identidade social numa mesma correlação de produções subjetivas do âmbito social e cultural, sendo este regido por elaborações estéticas, políticas e de cunho predominantemente participativo, ou seja, grupal. A própria produção da memória, isso é certo, tem como participante efetivo o outro, seja o outro pessoa ou coisa, objeto-recordação que possui uma memória (MARKS, 2010, p. 317) e uma significância memorial.

De acordo com Pollack (1992), a memória social ou individual tem como primazia os acontecimentos que ocorreram no percurso da história do indivíduo, e dos lugares, imaginados ou não, em que sucederam os acontecimentos. De fato, o espaço urbano das cidades é um local propício a produzir inúmeras situações sociais e de cunho marcante nos indivíduos. Sobretudo, as cidades são ambientes que produzem identidades culturais heterogêneas complexas, modos de convivência difusos, participações políticas diferenciadas ${ }^{1}$.

\footnotetext{
${ }^{1}$ A relação entre memórias, cidades, espaço urbano e construção de identidades culturais podem ter outras leituras levando em consideração que "na maior parte das vezes, a nossa percepção da cidade não é
} 


\section{SEMINÁRIO DE PESQUISA EM CIÊNCIAS HUMANAS - SEPECH \\ Humanidades, Estado e desafios didático-científicos \\ Londrina, 27 a 29 de julho de 2016}

Na concepção do autor,

A memória é um elemento constituinte do sentimento de identidade, tanto individual como coletiva, na medida em que ela é também um fator extremamente importante do sentimento de continuidade e de coerência de uma pessoa ou de um grupo em sua reconstrução de si (POLLACK, 1992, p. 5).

Além disso, a congruência entre memória e identidade social implica na elaboração de um passado que está, definitivamente, tatuado na construção dos sujeitos protagonistas de um determinado evento (GAGNEBIN, 2006). Esse evento pode fazer parte da vida dos sujeitos e contribuir para a construção de suas identidades. Contudo, essa memória, que é fruto de um passado e, por conseguinte, relato de um evento, acarreta na construção de identidades alocadas em espaços fronteiriços, cercado por delimitações simbólicas em ambientes periféricos. hibridismo,

Como aponta Stam (2010, p. 121), sobre o terceiro cinema e sua estética do

[...] Aqueles cuja história foi dispersa e diasporizada em vez de celebrada e incorporada no grandrécitcomo as grandes histórias dominantes e como aqueles cuja história foi frequentemente contada, dançada e cantada em vez de escrita, os povos primitivos foram obrigados a recriar seu passado a partir de pedacinhos e restos e de destroços da história.

Mais do que isso, Barbosa e Prysthon (2013, p. 11) comentam que:

Uma imagem é política quando cria, dentro de um contexto particular, um dissenso: expõe um ritmo, uma visibilidade, uma sensorialidade das coisas diferente de uma determinada ordem corrente, de uma partilha que, pelo viés dessa nova exposição sensível, apresenta um "erro de contagem". Quando essa imagem forja as condições de uma cena que torna visível o que antes era invisível e apresenta como som o que antes era um ruído, quando põe em cheque uma configuração de mundo ao propor outra.

Dessa forma, podemos afirmar que os filmes A Cidade é uma Só? e Branco Sai, Preto Fica, compreendem e constituem uma leitura estética e histórica, por meio do hibridismo de gênero, de um fato histórico e outro cultural, no contexto da construção da cidade de Ceilândia, evidenciando o sentido de fronteira, que se configura como "[...] o traço que separa imagem de si e imagem do outro, permitindo o autorreconhecimento e a construção do sentimento daquilo que é comum e daquilo que não é" (FRANÇA, 2010, p. 222).

íntegra, mas sim bastante parcial, fragmentária, envolvida noutras referências. Quase todos os sentidos estão envolvidos e a imagem é o composto resultante de todos eles” (LYNCH, 1960, p. 12). 


\section{SEMINÁRIO DE PESQUISA EM CIÊNCIAS HUMANAS - SEPECH \\ Humanidades, Estado e desafios didático-científicos \\ Londrina, 27 a 29 de julho de 2016}

Então, como o espaço urbano se constitui nesses filmes por meio da construção de uma narrativa que elenca o hibridismo e a fronteira como particularidades estéticopolíticas?
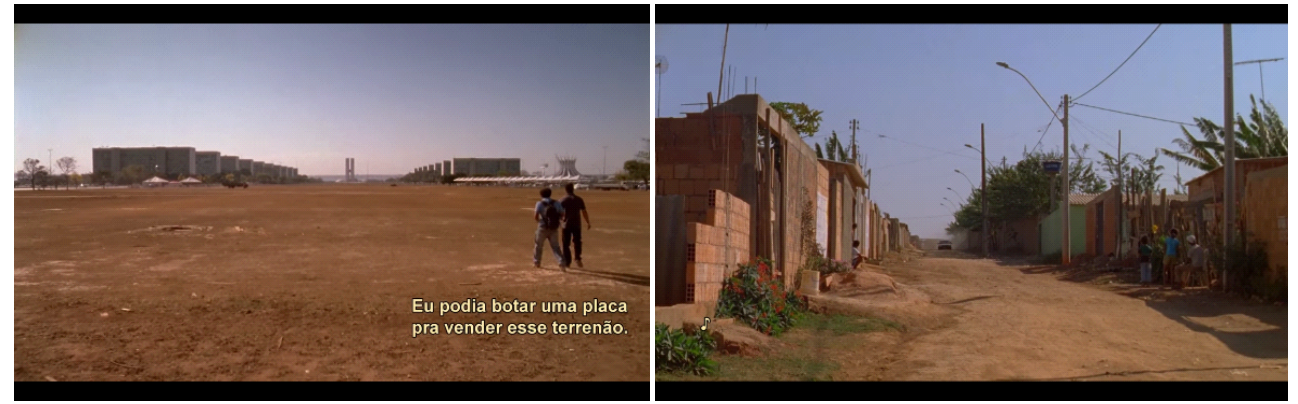

Figura 1: Cenas de A Cidade é uma Só?

É comum o cinema brasileiro contemporâneo aproveitar-se dos espaços urbanos das cidades que, a contento, transmitem sensibilidades e que, em certa medida, incorporam determinadas singularidades das personagens nas histórias dos filmes. Com isso, tem-se um espaço urbano constituído principalmente de indivíduos que são representações subjetivas e simbólicas do próprio espaço em questão, sendo, portanto, canais de transmissão e de significação de memórias.

A noção de espaço e paisagem no cinema, neste trabalho, segue as discussões de Costa (2015a, 2015b), que produz uma leitura espacial, identitária e cultural do cinema brasileiro contemporâneo, revelando sentidos políticos, híbridos e ideológicos e da produção nacional contemporânea. Além disso, os filmes analisados conferem reflexões multiculturais, polifônicas, situacionistas e histórico-políticas, por tratarem de acontecimentos reais regidos por uma lógica política da história de Brasília - DF.

Nos filmes escolhidos para este trabalho, as narrativas do espaço urbano de Ceilândia empregam diferentes maneiras de retirar da sua representação um discurso carregado de poder simbólico, assim como os momentos/etapas que antecederam o processo de construção da cidade ${ }^{2}$.

O processo de construção da cidade de Brasília é um momento de referência para compreender os deslocamentos subsequentes ao período de 1950 a 1960. Os homens e mulheres que para ali foram, em sua maioria partindo do nordeste do país, serviram como mão-de-obra para a construção da cidade, e logo ao término, foram favelizados e, em seguida, "transportados" para outra região. É assim que se inicia Ceilândia e outras cidades que estão no entorno da capital do Brasil.

\footnotetext{
2 Outros filmes da cinematografia brasileira já desenvolveram um diálogo com esse tema, como é o exemplo de Conterrâneos Velhos de Guerra (Vladimir Carvalho, 1991).
} 


\section{SEMINÁRIO DE PESQUISA EM CIÊNCIAS HUMANAS - SEPECH \\ Humanidades, Estado e desafios didático-científicos \\ Londrina, 27 a 29 de julho de 2016}
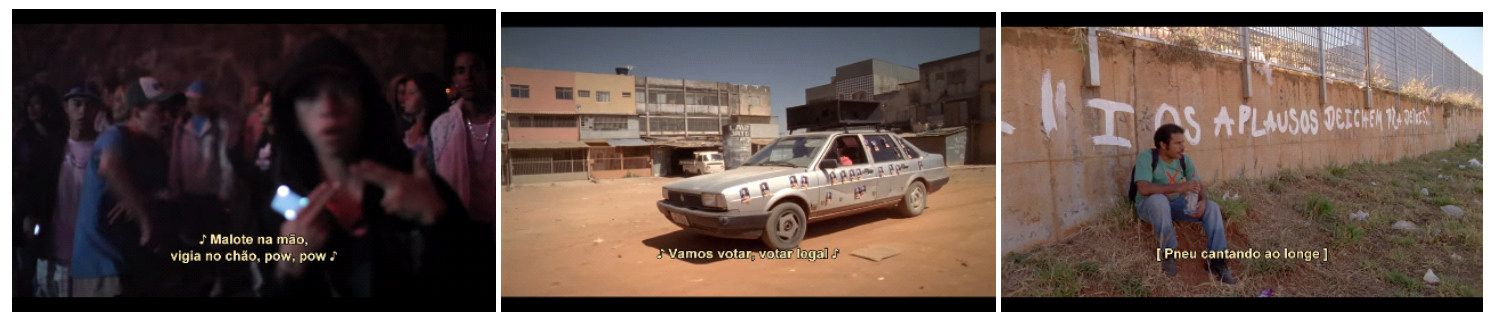

Figura 2: Cenas de A Cidade é uma Só?

O deslocamento das pessoas após a totalização da construção de Brasília é representado no filme $A$ Cidade é uma Só?, trazendo nas imagens o jingle da época que exemplifica a construção de um imaginário sobre uma "cidade que é boa para se viver/morar". A população composta, acima de tudo por pessoas negras, sustenta uma organização própria, empodera-se de um discurso, de um movimento cultural e de um sentido, uma identidade resgatada pela cultura Black.

Por outra perspectiva, o filme Branco Sai, Preto Fica representa de forma contundente os movimentos sociais surgidos a partir desse mesmo período, e toma mote para a sua narrativa um evento específico (as noites de dança) para categorizar uma série de componentes existentes na cidade de Ceilândia: a história cultural de um povo e os processos segregacionistas e racistas no território de Ceilândia.

Por meio de narrativas híbridas, o diretor Adirley Queiros concebe duas histórias que misturam ficção e documentário, gerando um sentido próprio em torno das questões problematizadas. Seus personagens confundem-se com pessoas da vida real: arquitetam memórias e histórias; estruturam correlações entre o passado e o futuro; e fomentam um espaço onde ações são orquestradas no âmbito fictício e real.
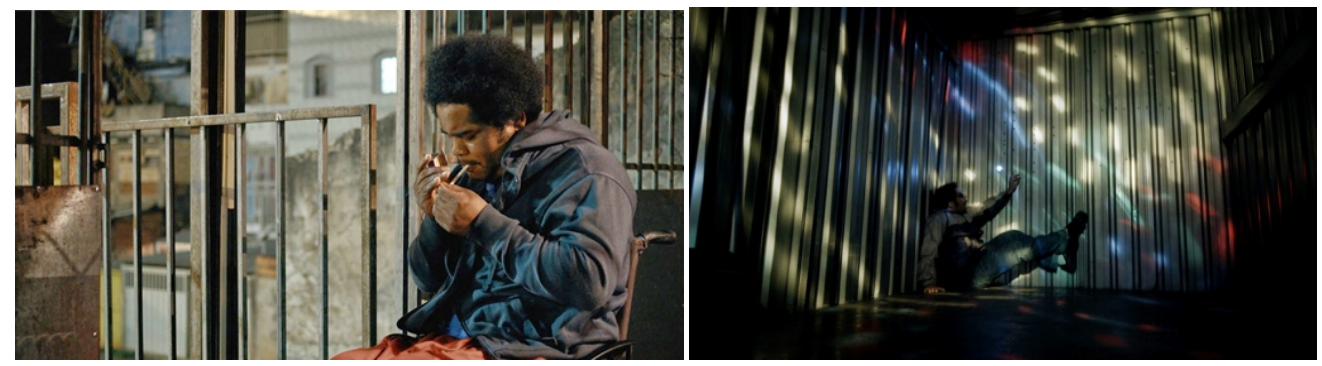

Figura 3: Cenas de Branco Sai, Preto Fica

O filme reorganiza não apenas uma história que, em certa medida, se perdeu no decorrer dos anos, como trabalha a memória sobre esse fato de uma maneira arraigada no tratamento das identidades culturais. Registrado em som e imagem, o evento no qual uma danceteria de Ceilândia é invadida por força militar, provocando o terror e exigindo que brancos saiam e pretos fiquem no local, como mostrado no filme, atravessa a noção de que a memória da cidade está ligada a documentos e lugares significantes, e "para tratar da memória de um lugar há que se trabalhar então na recuperação simultânea da história no e do lugar" (ABREU, 1998, p. 91).

$\mathrm{Na}$ ótica de Mesquita (2015), existe em A Cidade é uma Só? um jogo muito específico sobre drama e documento, correlacionando distintas narrativas na referência à história de um povo ou de um lugar. É a partir do uso de objetos-documentos que o 


\section{SEMINÁRIO DE PESQUISA EM CIÊNCIAS HUMANAS - SEPECH \\ Humanidades, Estado e desafios didático-científicos \\ Londrina, 27 a 29 de julho de 2016}

cineasta trabalha o tema da história (fotografias, imagens, gravações), convocando o passado para trabalhá-lo em sua relação com o presente.

Pelo trabalho de montagem, arquivos e encenações da atualidade se indagam, se "estranham", se questionam mutuamente. De um lado, o discurso utópico e liso da propaganda, que promete a cidade do futuro, é radicalmente confrontado pelas vivências miúdas atuais dos três protagonistas periféricos. Pela justaposição, a utopia modernista é conduzida a sua face distópica: violência social, partilha desigual e segregação espacial são realidades na Brasília "do futuro" (50 anos depois da inauguração, ou seja, no presente da filmagem). É como se a encenação do presente "afirmasse" às imagens de arquivo: não haverá esse futuro, ou melhor, não houve esse futuro (MESQUITA, 2015, p. 66).

É interessante perceber ainda sobre a contribuição do filme $A$ Cidade é uma Só? para os estudos de história e documentalidade no cinema brasileiro contemporâneo, como que as imagens fotográficas (os documentos) possuem sentidos determinantes para a construção das narrativas. Na leitura proposta por Furtado (2015), os documentos quando invertidos em suas categorias de apreciação simbólica no enredo do audiovisual, transformam-se em experiências estéticas, quando impingem um arder às imagens pelos objetos-documentos.

Essas reflexões nos levam a entender as circunstâncias simbólicas em que surgem as memórias sociais e os enredos memorialísticos inseridos na construção do contexto fílmico através do uso de muitos dispositivos de comunicação, perfazendo uma elaboração transmidiática no discurso fílmico.
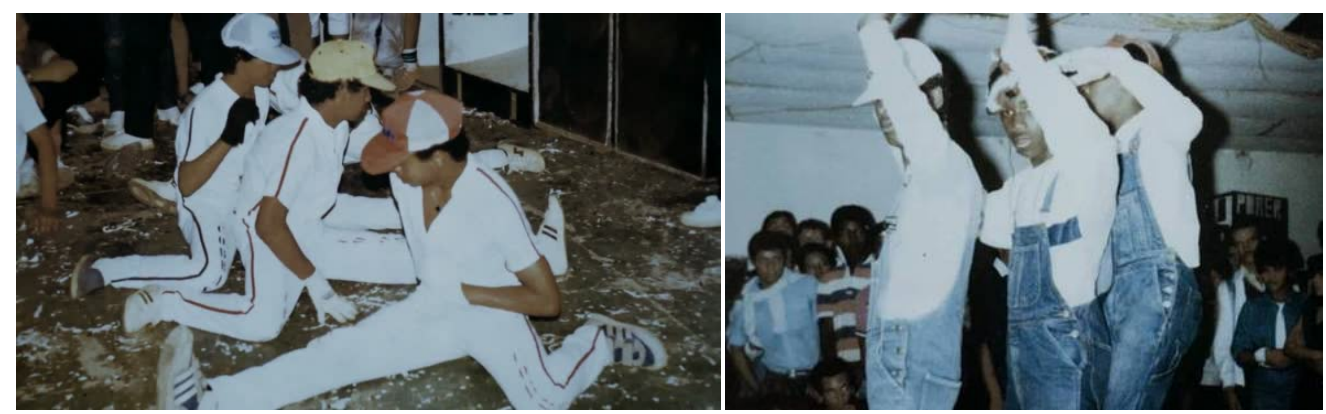

Figura 4: Cenas de Branco Sai, Preto Fica

Logo, como esse evento socialrepresentado no filme Branco Sai, Preto Fica, é projetado na teia histórica da cidade de Ceilândia? Os resquícios da cultura Black identificados no filme estão inseridos no contexto dos processos de dinamização da cultura, ocorrendo a junção entre diferentes modos de convivência, de representação e de absorção de identidades culturais (GARCÍA CANCLINI, 2008; HALL, 2003).

No entanto, a imagem do cinema é uma representação do mundo e dos processos (fenômenos, eventos, ritos sociais), sejam eles sociais e/ou espaciais, guiados por narrativas híbridas. É dessa forma que:

A imagem cinematográfica também tem como função recuperar a memória. O cinema é memória viva, uma vez que, constantemente 


\section{SEMINÁRIO DE PESQUISA EM CIÊNCIAS HUMANAS - SEPECH \\ Humanidades, Estado e desafios didático-científicos \\ Londrina, 27 a 29 de julho de 2016}

reproduzido, remete o passado ao presente, sem cessar. Ficção ou não, a imagem do filme, ainda que percebida individualmente, é coletivamente ativa, já que o julgamento pessoal é substituído pelo afeto coletivo, aumentando mais uma vez a sua força. $\mathrm{O}$ cinema não produz uma simples imagem, mas uma que, através da memória, transforma-se em um lugar de exercício dessa imagem e, simultaneamente, em uma interrogação sobre ela (FREITAS, 1997, p. $3)$.

Identificamos aqui, também, a cidade como um arcabouço de imaginações, cenários para subjetividades, palco para representações sociais, campo de disputas políticas e simbólicas. A cidade aparece como um dispositivo que representa a sociedade atual, que é mutante e industrial, eclética e multicultural. "As metrópoles têm se apresentado como palco de uma realidade complexa e múltipla em todos os sentidos", resultando em "segmentações tanto espaciais como simbólicas dos indivíduos" (DUTRA; RIBEIRO, 2013, p. 132) através da intersecção de diferentes modos de operações socioculturais. Em outras palavras, "parece-me que o cinema contemporâneo tomou para si a função (e o desafio) de construir novas imagens do espaço urbano (da cidade) que passem a fazer parte da própria paisagem urbana" (COSTA, 2006, p. 137).

Diante desse painel, a cidade representada nos filmes adquire status de espaço real onde personagens da vida real estão desenvolvendo ações prescritas nas normas sociais da sociedade. O que sabemos é que o cinema, principalmente aquele que em seu escopo se orienta por acontecimentos históricos e marcantes da realidade, funciona por similitude por meio dos espectadores, que acreditam fielmente nas histórias encenadas.

Dito isso, eles (nós) são (somos) cúmplices do cinema por que identificamos como real o que na verdade é a representação dele. Mas esse é um debate que precisa ainda ser revisto, por que durante muitos anos os imaginários das coisas do mundo são construídos pelas representações articuladas pelo cinema e outras mídias. Nessa discussão a problemática não reside em identificar o que são as representações das representações num mundo altamente imagético e profundamente estetizado (LIPOVETSKY, 2015), mas analisar o objeto cinematográfico em sua produção contínua de códigos, representações, imaginários e imagens da cidade e do espaço urbano reificados.

A cidade-satélite de Ceilândia, projetada nos filmes A Cidade é uma Só? eBranco Sai, Preto Fica, incorpora códigos, símbolos, representações e imaginários da cidade real de Ceilândia. Assim, não podemos acreditar que, ainda que exista narrativas que identificam o gênero documentário no modo de contar as duas histórias, que aquilo que é contado seja a mais pura e total representação da realidade, do espaço, das interações e comunicações na cidade de Ceilândia. Ao contrário disto, identificamos a cidade nos dois filmes e tomamos como análise a sua construção do espaço urbano e da representação dos eventos históricos e culturais que acompanharam o seu surgimento.

\section{CONSIDERAÇÕES FINAIS}

Em vista do exposto, este trabalho realizou a leitura de dois filmes contemporâneos brasileiros que trabalham com o hibridismo de gênero para construir 


\section{SEMINÁRIO DE PESQUISA EM CIÊNCIAS HUMANAS - SEPECH \\ Humanidades, Estado e desafios didático-científicos \\ Londrina, 27 a 29 de julho de 2016}

uma narrativa do espaço urbano e das paisagens de Ceilândia. Foi debatido o reconhecimento, através da ótica do cinema,da história do desenvolvimento de Ceilândia, cidade-satélite de Brasília, e os vestígios das memórias que trazem a tona novas percepções sobre o espaço urbano da cidade.

Dentro desse contexto, surgem as questões sobre a memória de um povo que se percebeu em contínuo processo de deslocamento, procurando desapropriar-se de um lugar que nunca foi o seu, Brasília. São esses temas que tratam os dois filmes aqui analisados, A Cidade é uma Só? e Branco Sai, Preto Fica, que indagam, ambos ao seu modo, como que se deu a transposição e o ajustamento dessas pessoas em outro espaço, e como esse novo espaço traduz as maneiras pelas quais eles conseguiram desenvolver modos de sobrevivência e sustentar uma cultura e identidade próprias.

Consequentemente, os conflitos e as relações de poder que circundam essas duas formas de representação social, os oprimidos pelo Estado e o Estado que os oprime na figura da força policial sempre presente nas narrativas dos dois filmes, inspira debates se não sobre a potência da imagem cinematográfica como dispositivo de reaver ou de tornar novamente evidente o contato entre duas classes que estão em constante conflito político e simbólico. Os dois filmes mostram, assim, que a violência resultante desse conflito é mais simbólica do que física, mais presente nas entrelinhas da história cultural do que nas páginas de destaque dos livros de história.

A representação que o cinema fornece dessas duas histórias particulares da construção de Brasília e as consequentes transformações sociais e culturais que se seguirem ao seu entorno, apenas confere que a imagem produzida pelo cinema, mesmo que usufruindo de documentos originais do evento o qual trata, não é absolutamente um retrato do que aconteceu no passado, no presente e o que irá acontecer no futuro apresentado como distópico. O jogo memorialístico e documental incorporado no discurso de ambos os filmes, na verdade, são caminhos traçados no intuito de gerenciar na plasticidade que o cinema autoriza a realidade. $\mathrm{O}$ espaço urbano, as memórias e os documentos de registro configuram como canais por onde o discurso se desenha, contribuindo ou dificultando, por meio das narrativas, na missão de enquadrar uma noção dos fatos e das coisas do mundo.

\section{REFERÊNCIAS}

ABREU, Maurício de Almeida. Sobre a memória das cidades. Revista da Faculdade de Letras - Geografia I série, vol. XIV, Porto, p. 77-97, 1998.

BARBOSA, André Antônio. PRYSTHON, Angela. Uma política do passado: a história em Benjamin, a memória em Bergson. Revista Fronteiras - estudos midiáticos, 15 (1): 3-12, jan./abr., 2013.

COSTA, Maria Helena B. V. Social and Cinematic Landscape in Neighbouring Sounds.Mercator, Fortaleza, v. 14, n. 3, p. 27-43, set./dez., $2015 a$.

COSTA, Maria Helena B. V. Space, Time, Cinema and Cultural Geography: The Contemporary Brazilian Cinematic City. InternationalJournalofArts\&Sciences, 08 (07): 97-114, 2015 b. 


\section{SEMINÁRIO DE PESQUISA EM CIÊNCIAS HUMANAS - SEPECH \\ Humanidades, Estado e desafios didático-científicos \\ Londrina, 27 a 29 de julho de 2016}

COSTA, Maria Helena B. V. Imagens e narrativas da violência: o cinema, o espetáculo e a perspectiva pós-moderna. In: FREIRE-MEDEIROS, Bianca e COSTA, Maria Helena Braga e Vaz (Orgs.). Imagens Marginais. Natal: EDUFRN, 2006, pp. 131 146.

DUTRA, Rogéria Campos de Almeida. RIBEIRO, Nádia Oliveira Vizotto. A Antropologia Urbana no Brasil. Teoria e Cultura, Juiz de Fora, v. 8, n.1, p. 127-138, jan./jun., 2013.

FRANÇA, Andréa. Imagens de itinerância no cinema brasileiro. In: FRANÇA, Andréa e LOPES, Denilson (Orgs.). Cinema, globalização e interculturalidade. Santa Catarina: Argos, 2010, pp. 219 - 242.

FREITAS, Cristiane. Da memória ao cinema. Logos - Comunicação e Universidade, v. 4, n.2, p. 16-19, 1997.

FURTADO, Beatriz. Das sobrevivências que queimam. In: BRANDÃO, Alessandra e LIRA, Ramayana (Orgs.). A sobrevivência das imagens. Campinas: Papirus, 2015, pp. $77-86$.

GAGNEBIN, Jeanne Marie. Lembrar. Escrever. Esquecer. São Paulo: Editora H34, 2006.

GARCÍA CANCLINI, Néstor. Culturas Híbridas: Estratégias para Entrar e Sair da Modernidade. São Paulo: Editora da Universidade de São Paulo, 2008.

HALL, Stuart. Da diáspora: Identidades e mediações culturais. Belo Horizonte: Editora UFMG; Brasília: Representação da UNESCO no Brasil, 2003.

LYNCH, Kevin. A imagem da cidade. Rio de Janeiro: Edições 70, 1960.

LIPOVETSKY, Gilles. A Estetização do Mundo: viver na era do capitalismo artista. São Paulo: Companhia das Letras, 2015.

MARKS, Laura U. A memória das coisas. In: FRANÇA, Andréa e LOPES, Denilson (Orgs.). Cinema, globalização e interculturalidade. Santa Catarina: Argos, 2010, pp. $309-344$.

MESQUITA, Cláudia. Drama e documento, atualidade e história no cinema brasileiro contemporâneo. In: BRANDÃO, Alessandra e LIRA, Ramayana (Orgs.). A sobrevivência das imagens. Campinas: Papirus, 2015, pp. 63 - 76.

POLLACK, Michael. Memória e Identidade Social. Estudos Históricos, Rio de Janeiro, vol. 5, n. 10, p. 200-212, 1992. 
STAM, Robert. Para além do Terceiro Cinema: estéticas do hibridismo. In: FRANÇA, Andréa e LOPES, Denilson (Orgs.). Cinema, globalização e interculturalidade. Santa Catarina: Argos, 2010, pp. $111-136$. 